\title{
Field calibration of optical sensors for measuring suspended sediment concentration in the western Mediterranean*
}

\author{
J. GUILLÉN ${ }^{1}$, A. PALANQUES ${ }^{1}$, P. PUIG ${ }^{1}$, X. DURRIEU DE MADRON² \\ and F. NYFFELER ${ }^{3}$ \\ ${ }^{1}$ Instituto de Ciencias del Mar (C.S.I.C.), Paseo Joan de Borbó s/n 08039 Barcelona, Spain. E-mail: jorge@ @icm.csic.es \\ ${ }^{2}$ Centre de Formation et de Recherche sur L'Environnement Marin, CNRS-UP UMR 5110, 52 Avenue de Villeneuve, \\ 66860 Perpignan Cedex France \\ ${ }^{3}$ Limnocéane, University of Neuchâtel, 11 rue Emile Argand, 2007 Neuchâtel, Switzerland
}

\begin{abstract}
SUMMARY: The water turbidity measured with optical methods (transmittance and backscattering) is usually expressed as beam attenuation coefficient (BAC) or formazin turbidity units (FTU). The transformation of these units to volumetric suspended sediment concentration (SSC) units is not straightforward, and accurate calibrations are required in order to obtain valuable information on suspended sediment distributions and fluxes. In this paper, data from field calibrations between BAC, FTU and SSC are presented and "best-fit" calibration curves are shown. These calibrations represent an "average" from different marine environments of the western Mediterranean (from estuary to continental slope). However, the general curves can only be applied for descriptive or semi-quantitative purposes. Comparison of turbidity measurements using the same sensor with different calibration ranges shows the advantage of simultaneously combining two instruments calibrated in different ranges when significant changes in suspended sediment concentrations are expected.
\end{abstract}

Key words: sediment concentration, field calibrations, NW Mediterranean.

\section{INTRODUCTION}

Suspended sediment concentration (SSC) in the marine environment must be measured to study the distribution patterns of suspended sediment and its associated components, including contaminants and living organisms. These measurements are also necessary to quantify sediment fluxes across and along continental margins. Common techniques are gravimetric analysis, optical instruments and, more recently, acoustic sensors. The advantages and disadvantages of the different methods have been

\footnotetext{
*Received April 17, 2000. Accepted October 11, 2000.
}

analysed in previous studies (e.g. Conner and De Visser, 1992; Black and Rosenberg, 1994). Measurements are obtained from turbidimeter and Niskin bottles coupled with CTD probes that record vertical profile or from moored instruments that incorporate turbidimeters to record time series.

Whereas the gravimetric technique involves the direct measure of the particle concentration, the indirect methods consist in the measurement of different water properties related to the suspended sediment concentration. Measurement with optical instruments depends greatly upon a variety of parameters such as particle size, composition, and shape, as well as environmental characteristics (Bunt et al., 
1999; Sutherland et al., 2000). For these reasons careful calibration and interpretation are required.

The interpretation of the turbidity data can be complex because of the high spatial-temporal variability of the suspended sediment in the marine environment, the utilisation of devices based on different properties and the absence of accurate field or laboratory calibrations. When direct calibration with "in situ" sediment is unavailable, turbidity can be expressed as a "beam attenuation coefficient" (BAC) or in "Formazin Turbidity Units" (FTU). Both measurement units are proportional to the SSC of the water column, although universal transformations cannot be established. In addition, calibration curves from BAC or FTU to volumetric concentrations only have a local validity because calibration coefficients remain relatively constant only when sediment characteristics do not change.

This paper presents calibrations between BAC and FTU units with respect to SSC measured with gravimetric methods. These calibrations were carried out in the western Mediterranean during different field campaigns (Fig. 1). The aim of the study is to provide information about the expected variability of the calibration curves under different environments in this region where field calibrations are scarce (Durrieu de Madron et al., 1990; 1994; Puig and Palanques, 1998). The results may be useful for obtaining a semi-quantitative approach of turbidity data for which "in situ" calibration is not available. In addition, this information adds a criterion for choosing the appropriate sensor and measuring ranges for future field studies in these environments. This is especially relevant for the new turbidimeter sensor manufactured by Aanderaa because of the lack of previous field calibrations.

\section{INSTRUMENTS AND METHODS}

Three different methods were used for measuring SSC: the gravimetric method, transmissometers (measuring light transmittance) and turbidimeters (measuring light scattering).

Gravimetric method: Seawater samples were taken with Niskin bottles (alone or coupled to a CTD) or by pumping water with immersed pumps. The selection of each sampling point was based on the vertical profile of temperature, salinity, fluorescence and light transmittance recorded previously with the CTD during the downward cast. For each sample, between 1.5 and 6 litres of seawater were vacuum-filtered into a pre-weighed Nuclepore filter $(0.4 \mu \mathrm{m}$ pore size) and the concentration of the suspended sediment was estimated gravimetrically. Gravimetric analysis produced direct and accurate suspended sediment concentration measurements, but this method is inadequate for measuring rapid temporal variations in the field. Despite the inevitable presence of measurement uncertainties, the information obtained from filtered sediments is usually considered as the "true" concentration used for calibration of the other methods.

The transmissometer (Sea Tech Inc.) is an optical sensor that can be coupled to both a CTD and a current meter. It uses a light emitting diode with a wavelength of $660 \mathrm{~nm}$ and a beam diameter of 15 $\mathrm{mm}$. The receiving sensor is located at some fixed distance from the emitting diode. The return signal is inversely proportional to the concentration of suspended particles in the water (Baker and Lavelle, 1984; Bishop, 1986), although the use of the transmissometer is generally restricted to fine sediments. In this study, the Sea Tech transmissometer with a $25 \mathrm{~cm}$ pathlength was coupled to a Neil Brown CTD probe or to a RCM-7 Aanderaa current meter.

Optical Backscatter Sensors are nephelometers that measure water turbidity by detecting infrared radiation scattered from suspended matter (Downing and Beach, 1989; Ludwig and Hanes, 1990; Conner and De Visser, 1992; Green and Boon, 1993; Black and Rosenberg, 1994). Previous studies demonstrated the linear response of backscatter sensors to changes in sediment concentration. In this study, two types of optical sensors previously calibrated with Formazin were employed: a) an OBS-3 sensor by D\&A (0-1000 FTU); b) and turbidity sensors manufactured by Aanderaa (0-5, 0-20 and 0100 FTU). Although the OBS response to suspended sediment is well known (e.g. Sutherland et al., 2000), the turbidimeter supplied by Aanderaa is relatively new and hardly any information about field calibration is available in the scientific literature.

Forward light scattering meter is a nephelometer developed by IFREMER (Vangriesheim et al., 1992). Light from a thin, collimated red source (635 $\mathrm{nm}$ ) is forward-scattered by suspended particles and measured by a ring-shaped detector between $2^{\circ}$ and $5^{\circ}$ off the axis of the beam. Attenuation of the light along the optical path is corrected by comparing the scattered light intensity to the collimated beam intensity measured by a second detector located at the centre of the ring detector. In this study, the nephelometer was calibrated versus a standard For- 
mazine solution and the turbidity expressed as Formazine Turbidity Unit (FTU).

Calibrations from BAC or FTU to SSC have linear relationships calculated by the least-square method. The significance of the correlation coefficient was tested using Student's t-test. The error on the regression equation, estimated by the $95 \%$ confidence limits, is defined by:

$$
\begin{aligned}
& S S C_{\text {low }}=\overline{S S C}+b(C-\bar{C})-t_{0.05} S \\
& S S C_{u p}=\overline{S S C}+b(C-\bar{C})-t_{0.05} S
\end{aligned}
$$

where $\overline{S S C}$ is the mean suspended sediment concentration, $\overline{\mathrm{C}}$ is the mean intensity of the measured parameter (BAC or FTU), b the slope of the linear relationship, and $t_{0.05}$ the critical value of the Student's distribution at the 5\% significance level and n-2 degrees of freedom. The variable $\mathrm{S}$ is expressed as:

$$
S=\sqrt{\frac{S_{S S C}^{2}}{S_{C}^{2}}\left(\frac{1-r^{2}}{n-2}\right)\left(\frac{S_{C}^{2}(n-1)}{n}+(C-\bar{C})^{2}\right)}
$$

where $S_{S S C}^{2}$ is the variance of suspended sediment concentration, $S_{C}^{2}$ is the variance of the measured parameter (BAC or FTU), $r$ is the correlation coefficient and $\mathrm{n}$ is the number of measurements (Sokal and Rohlf, 1981).

Comparison of simultaneous turbidity measurements obtained with different sensors was made by calculating a functional linear relationship using the major axis method (Sokal and Rohlf, 1981). The departure of the regression slope from the unity and the regression origin from zero were tested using a Student's t-test.

\section{Beam attenuation coefficient (BAC)}

The BAC is the water turbidity unit usually given for transmissometer measures. The transmissometer records the voltage $(\mathrm{V})$ proportional to the light intensity at a distance (L) from the light source:

$$
\mathrm{V}=\mathrm{V}_{0} \mathrm{e}^{-\alpha \mathrm{L}},
$$

where $\mathrm{V}_{0}$ is the voltage at $\mathrm{L}=0$ and $\alpha$ is the total BAC. The total BAC has contributions from pure water $\left(\alpha_{\mathrm{w}}\right)$, suspended matter $\left(\alpha_{\mathrm{p}}\right)$ and dissolved organic matter $\left(\alpha_{\mathrm{y}}\right)\left(\alpha=\alpha_{\mathrm{w}}+\alpha_{\mathrm{p}}+\alpha_{\mathrm{y}}\right)$. Usually it is assumed that $\alpha_{\mathrm{y}}=0$ (Jerlov, 1968), and

$$
\alpha_{\mathrm{p}}=(-1 / \mathrm{L}) \ln (\mathrm{V} / \mathrm{Vw}) \text {, }
$$

where $\mathrm{Vw}$ is the normalisation voltage in pure water which contains no suspended matter. For practical purposes, $\mathrm{Vw}$ can be considered as the maximum voltage measured during a field campaign and the calculated $\alpha_{\mathrm{p}}$ reflects the variations over this background level (Sherwood et al., 1994).

The suspended particle BAC $\left(\alpha_{p}\right)$ for a given particle size $\mathrm{D}$ is related to the number of particles $(\mathrm{N})$ per unit volume and to the cross-sectional area:

$$
\alpha_{\mathrm{p}}=\mathrm{N} \mathrm{Q} \pi \mathrm{D}^{2} / 4,
$$

where $\mathrm{Q}$ is the effective area coefficient for light attenuation (Spinrad et al., 1983). Assuming spherical particles of density $\rho_{\mathrm{s}}$, the sediment concentration is defined as:

$$
\mathrm{SSC}=\left(2 \rho_{\mathrm{s}} \mathrm{D} / 3 \mathrm{Q}\right) \alpha_{\mathrm{p}}=\mathrm{B} \alpha_{\mathrm{p}},
$$

where B is the calibration slope, a coefficient directly related to the sediment grain size (Baker and Lavelle, 1984).

From laboratory calibrations using different grain size fractions, a single relation was established (Moody et al., 1987; Wiberg et al., 1994):

$$
\mathrm{B}=\mathrm{k} \mathrm{D} \text {, }
$$

being $\mathrm{k}$ a coefficient which ranges from 1.12 to 3.4. The wide range of values for the slope coefficient (B) suggests that other factors besides the sediment grain size can modify the relation between the particle beam attenuation coefficient and the suspended sediment concentration.

\section{Formazin Turbidity Units (FTU)}

Both transmissometers and optical backscatter sensors can be calibrated using commercially available turbidity standards. The 4000-FTU formazin is the most frequently employed product and units are then called FTU.

FTU measurements can be converted into suspended sediment concentration data (SSC) using a simple regression equation:

$$
\mathrm{SSC}=\mathrm{m} * \mathrm{FTU}+\mathrm{C}_{0},
$$

where $\mathrm{m}$ is the slope and $\mathrm{C}_{0}$ the $\mathrm{y}$-intercept value of the regression.

The slope $m$ is mainly a function of the grain size of suspended sediment. While the size of the sand 
TABLE 1. - Data used for calibration of beam attenuation coefficient and formazin turbidity units versus suspended sediment concentration (see location in Fig. 1).

\begin{tabular}{|c|c|c|c|c|}
\hline SURVEY & DATE & AREA & ARRAY & SENSOR \\
\hline 1.- Concentra & 1993-1994 & Barcelona margin & CTD & Sea Tech \\
\hline 2.- Suivilion & $1995-1996$ & Gulf of Lions & CTD & Sea Tech \\
\hline 3.- Fans & 1996-1997 & Ebro margin & CTD & Sea Tech \\
\hline 4.- Impact'97 & Jul.-1997 & Llobregat shelf & CTD & Sea Tech \\
\hline 5.- Impact'98 & Feb.-1998 & Maresme shelf & CTD & Sea Tech \\
\hline 6.- Fluxalb & Oct.-1998 & Alboran margin & CTD & RCM-9 \\
\hline 7.- Doñana & Oct. -1998 & Guadalquivir & CTD & RCM-9 \\
\hline 8.- Ecomarge & 1986-1988 & North Balearic Sea & CTD & Nephelometer \\
\hline 9.- Banyuls & Oct.-1999 & Banyuls shelf & Mooring & RCM-9 \\
\hline 10.- Laboratory & Jun.-1999 & Mud sediment & - & OBS-3 \\
\hline
\end{tabular}

grains in suspension does not greatly affect the gain of the sensors, the sensor's sensitivity to suspended mud is significantly higher than its sensitivity to sand (Ludwig and Hanes, 1990). Considering a laboratory calibration independently for mud and sand fractions, the slope $m$ of the regression curve (Equation 6) shows values of 1.39-1.81 for the silt fraction and of 8.13-10.4 for the sand fraction (Green and Boon, 1993). Therefore, the silt sensitivity exceeds the sand sensitivity by a factor of 5-6. For a mixed sediment, the total suspended sediment concentration can be adequately estimated (error $<13 \%$ ) by adding the concentration of silt and sand calculated independently using their respective $m$ coefficients. An extensive analysis of the grain size effect in the OBS measurement of suspended sediment concentration was presented by Madsen et al. (1993).

\section{RESULTS AND DISCUSSION}

\section{Beam attenuation coefficient versus SSC}

Calibration of the BAC was carried out using data from six field campaigns conducted in different areas of the western Mediterranean Sea (Table 1 and Fig. 1). BAC measured during these cruises ranged from 0.4 to $14 \mathrm{~m}^{-1}$. Bivariate plots between the SSC measured with gravimetric methods and the BAC display a linear correlation with different degrees of fitness (Fig. 2). The slope (B) of the relation between SSC and $\alpha_{\mathrm{p}}$ (Equation 4 ) varies between 1.32 and 1.71. The slope of the regression changes among different study areas as well as in successive campaigns in the same area (FANS surveys), where temporal variability was also observed $(\mathrm{B}=1.33$ 1.6) (Guillén et al., 1998).

In general, the calibration curves between beam attenuation and SSC reported in this study display a

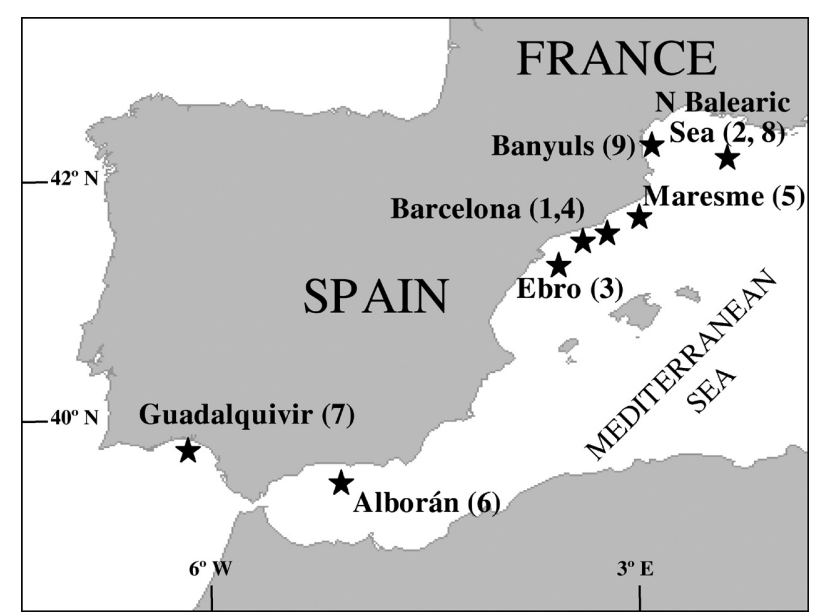

FIG. 1. - Location of field surveys.

moderate variability. Since the slope B is directly related to the sediment grain size (Equation 5), it can be considered that grain size variability of the suspended sediment during cruises was low. When all the calibration samples are considered together, the calibration equation is:

$$
\mathrm{SSC}=1.43 \alpha_{(\mathrm{p}+\mathrm{w})}-0.26\left(\mathrm{r}^{2}=0.85\right),
$$

which seems a reasonable approach for semi-quantitative purposes (Fig. 3). This relationship is representative for shelf and slope areas of the NW Mediterranean that receive fine sediment from rivers and usually have suspended sediment concentrations lower than $5 \mathrm{mg} / \mathrm{l}$.

\section{Formazin turbidity units versus SSC}

Measurements carried out with turbidimeters previously calibrated with a formazin solution were compared with gravimetric measurements of SSC in a variety of marine environments (Fig. 4; Table 1). 

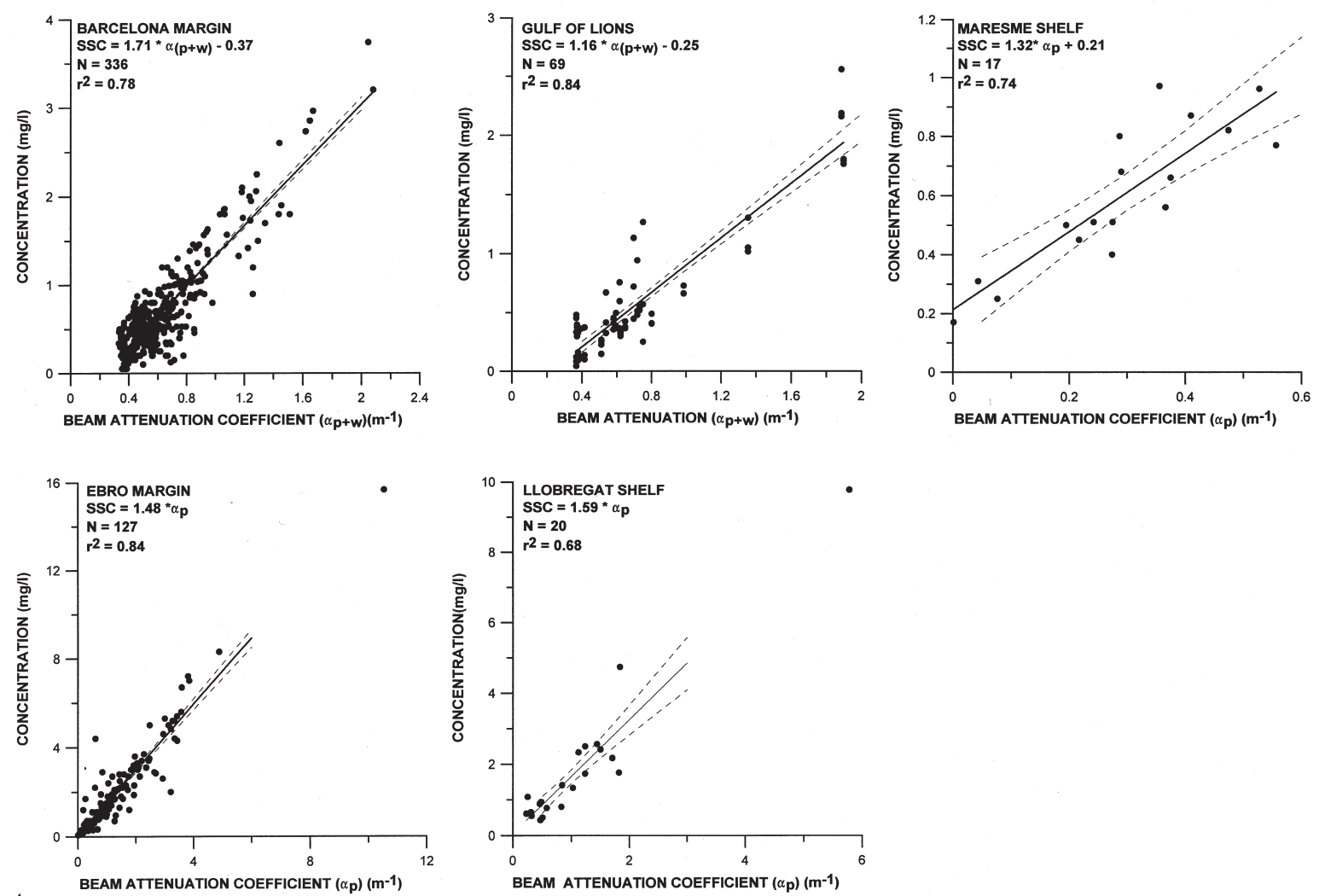

FIG. 2. - Calibration between beam attenuation coefficient and suspended sediment concentration during different field campaigns $(\mathrm{SSC}=$ suspended sediment concentration in $\mathrm{mg} / \mathrm{l} ; \alpha$ is beam attenuation coefficient caused by suspended sediment particles $\left(\alpha_{\mathrm{p}}\right)$ and suspended sediment particles and sea water $(\alpha \quad$ ); $\mathrm{N}=$ number of samples) (dashed lines indicate the error on the regression equation estimated by the $95 \%$ confidence limits). Correlation coefficients for every calibration are highly significant (probability $<0.1 \%$ ).

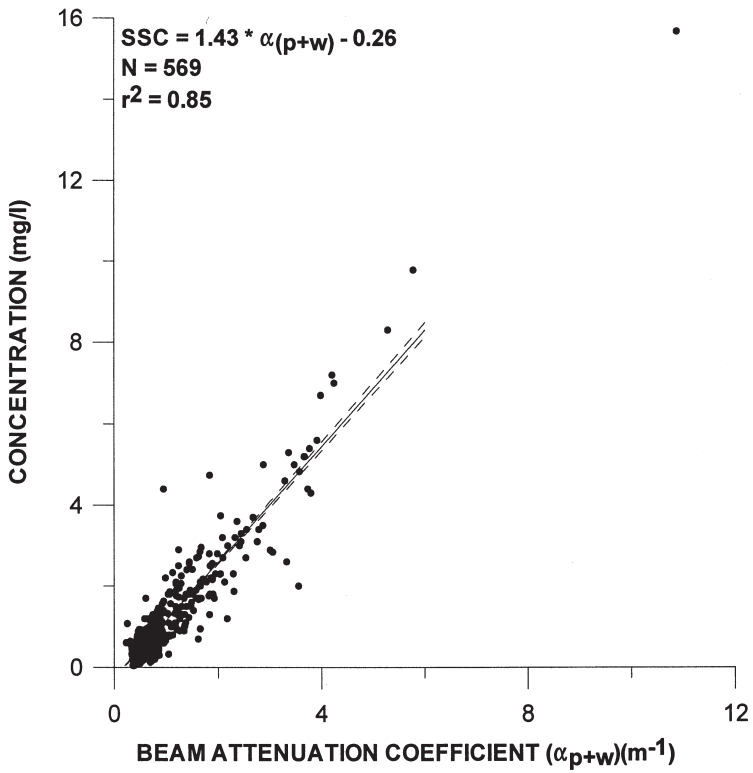

FIG. 3. - General calibration between beam attenuation coefficient and suspended sediment concentration using the available data ( $\mathrm{SSC}=$ suspended sediment concentration in $\mathrm{mg} / \mathrm{l} ; \mathrm{C}_{(\mathrm{p}+\mathrm{w})}=$ beam attenuation coefficient related to particles and marine ${ }^{(p+w)}$ water; $\mathrm{N}=$ number of samples) (dashed lines indicate the error on the regression equation estimated by the $95 \%$ confidence limits). The correlation coefficient is highly significant (probability $<0.1 \%$ ).
Estuarine, shelf and slope environments were sampled as well as laboratory specific tests. Turbidity values ranged from 0.07 to 400 FTU and the concentration from 0.1 to $700 \mathrm{mg} / \mathrm{l}$. The calibration slope for each set of data ranged from 0.24 to 1.71 . These significant differences in the calibration slope are related to the range of the suspended sediment concentration and/or the marine environment considered: the calibration slope is lower than 0.8 in the "deep" environments where the SSC is usually lower than $1 \mathrm{mg} / \mathrm{l}$ and is higher than 1.2 in shallower environments with a larger SSC. Therefore, the calibration curve between measurements in FTU and SSC display an increasing slope from low to high concentrations. Since the slope of the linear correlation is also a function of the characteristics of the suspended sediment particles, differences in the slope could also reflect differences in the suspended sediment grain size (finer in deeper areas), composition (organic matter content), or multiscattering.

When all the calibration points are considered, the best fit is obtained from the equation:

$$
\mathrm{SSC}=1.74 * \mathrm{FTU}-1.32,\left(\mathrm{r}^{2}=0.99\right),
$$



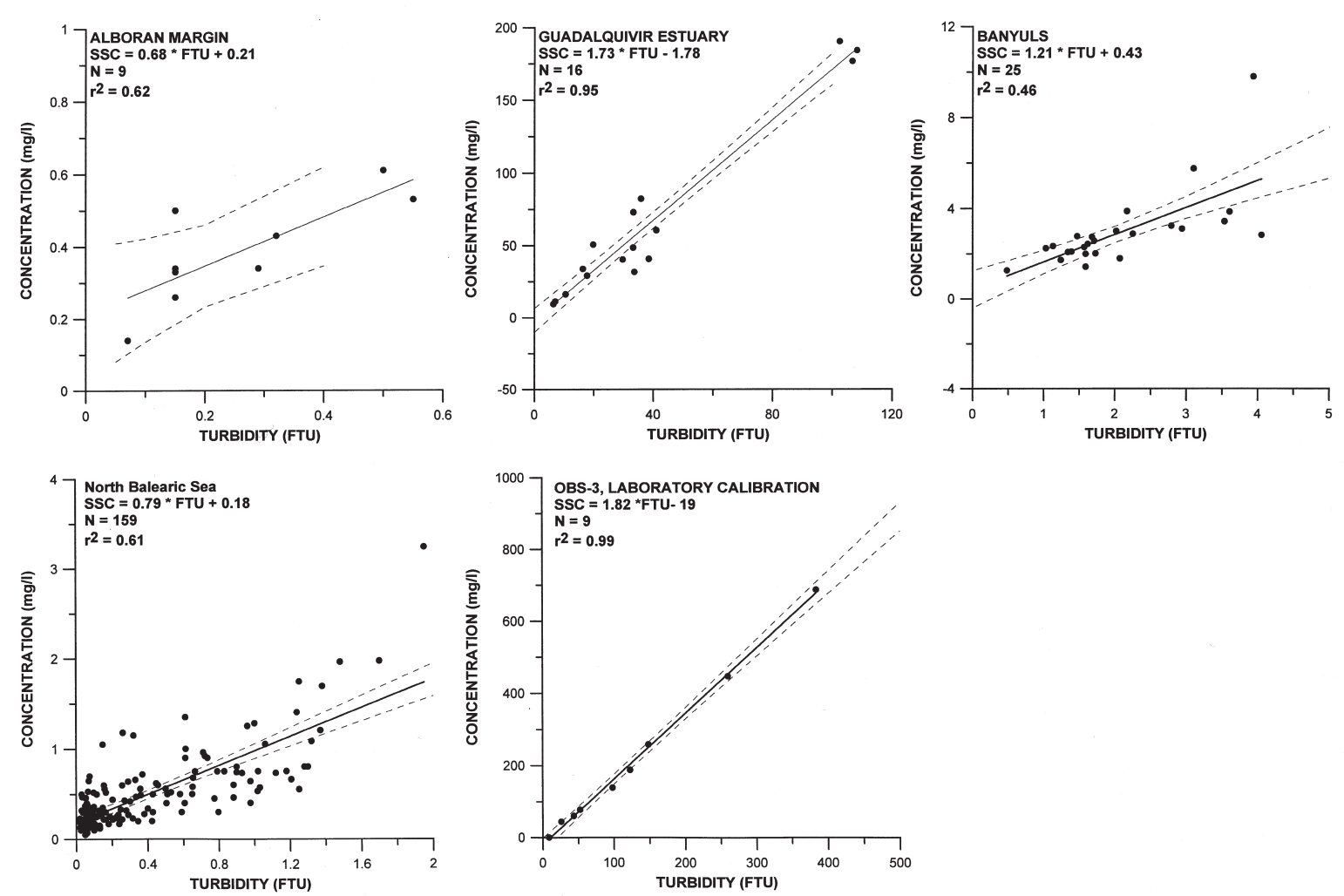

FIG. 4. - Calibration between formazin turbidity units and suspended sediment concentration during different field campaigns and laboratory experiment ( $\mathrm{SSC}=$ suspended sediment concentration in $\mathrm{mg} / \mathrm{l}$; FTU = turbidity in formazin units; $\mathrm{N}=$ number of samples) (dashed lines indicate the error on the regression equation estimated by the $95 \%$ confidence limits). Correlation coefficients for every calibration are highly significant (probability $<0.1 \%$ ). The Alboran campaign displays a correlation coefficient that is significant (probability $<5 \%$ ).

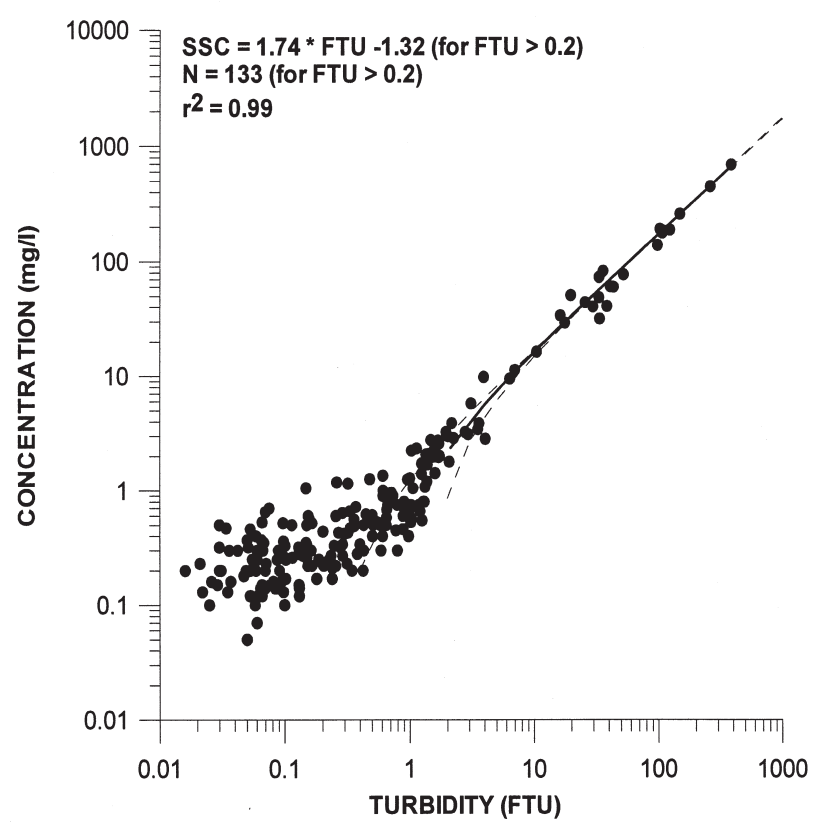

FIG. 5. - General calibration between formazin turbidity units and suspended sediment concentration using the available data $(\mathrm{N}=$ number of samples, dashed lines indicate the error on the regression equation estimated by the $95 \%$ confidence limits). The correlation coefficient is highly significant (probability $<0.1 \%$ ). which is an approximation of sediment concentrations for fine particles in suspension as measured by different devices in FTU units (Fig. 5).

Although no direct field calibrations of SSC sand or mixed sediment were made, indirect evidence suggests that the calibration curve changes significantly with the sediment grain size. One OBS-3 sensor was calibrated in the laboratory using bottom sediment from the deployment site ( $88 \%$ sand and $12 \%$ mud). This sensor was located on an instrumented tripod at the same distance above the seabed $(0.98 \mathrm{~m})$ as an Aanderaa nephelometer (0-20 FTU) in the Ebro delta shoreface (12 $\mathrm{m}$ water depth) during two campaigns. The average suspended sediment concentrations measured with the OBS-3 sensor (2400 samples during 20 minutes) were compared with average values of a 0-20 FTU ranged Aanderaa turbidimeter (4 samples during 20 minutes). The temporal evolution of the turbidity measured for the two sensors displays a similar behaviour. The best fit relation between OBS-3 derived SSC and Aanderaa turbidity is achieved with the power curve (Fig. 6): 

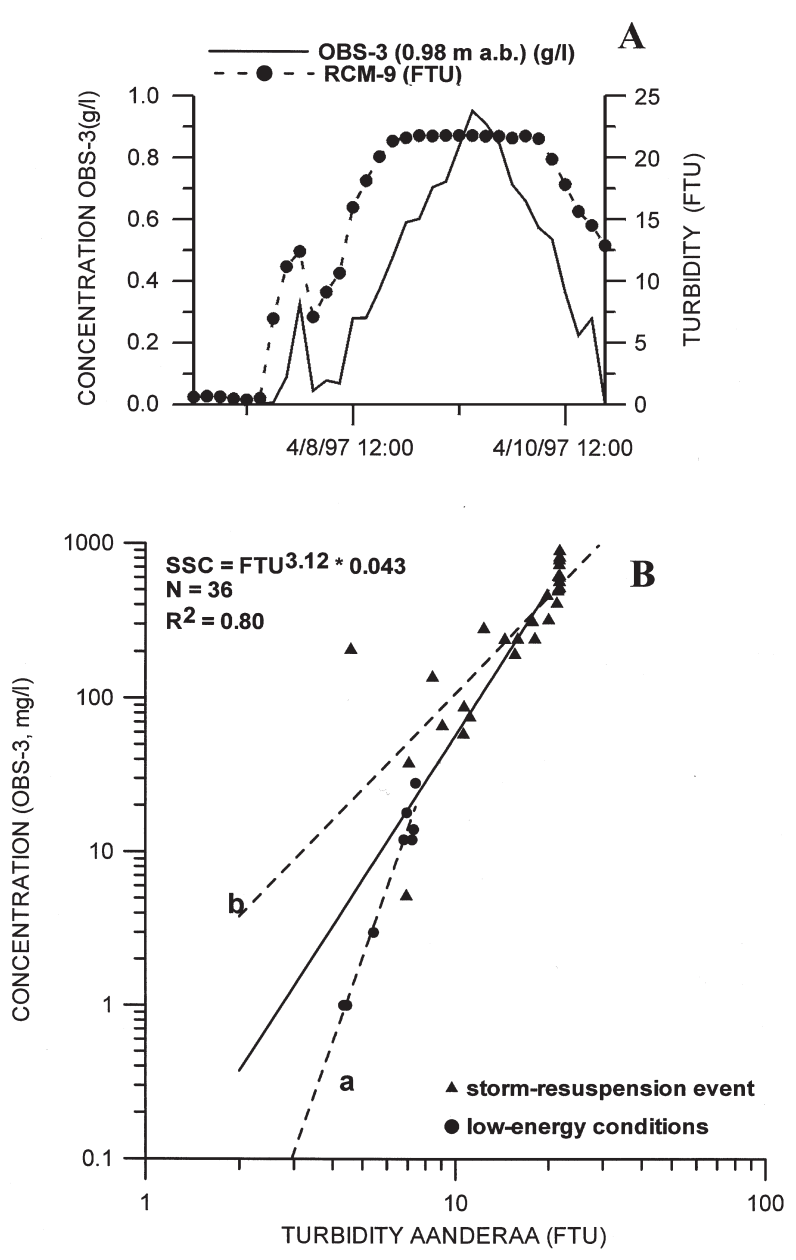

FIG. 6. - Simultaneous turbidity measurements using an OBS-3 device (sediment calibrated) and an Aanderaa turbidimeter (0-20 FTU). A) temporal evolution during wave-storm conditions. B) relationships between OBS-3 and Aanderaa turbidimeter (range of 0-20 FTU). Dashed lines indicate the best fit for wave-storm resuspension events (fit curve b) and low-energy conditions (fit curve a), and the solid line represents the best fit of all integrated values, that corresponds to the calibration equation.

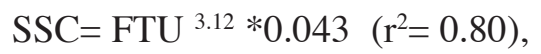

or by a linear relationship

$$
\mathrm{SSC}=17.1 * \mathrm{FTU}-68.4\left(\mathrm{r}^{2}=0.61\right)
$$

which is significantly different to the calibration curve obtained from Equation (8). The RCM9 0-20 FTU turbidimeter sensor was out of range when the SSC of mixed suspended sediment (sand and mud) was higher than $800 \mathrm{mg} / \mathrm{l}$ (Fig. 6). However, if we use the former calibration curve for suspended muddy sediment (Fig. 5) this sensor would had been out of range for SSC higher than $30 \mathrm{mg} / \mathrm{l}$. This is indicative of the strong effect of the grain size to calibrate FTU into SSC.
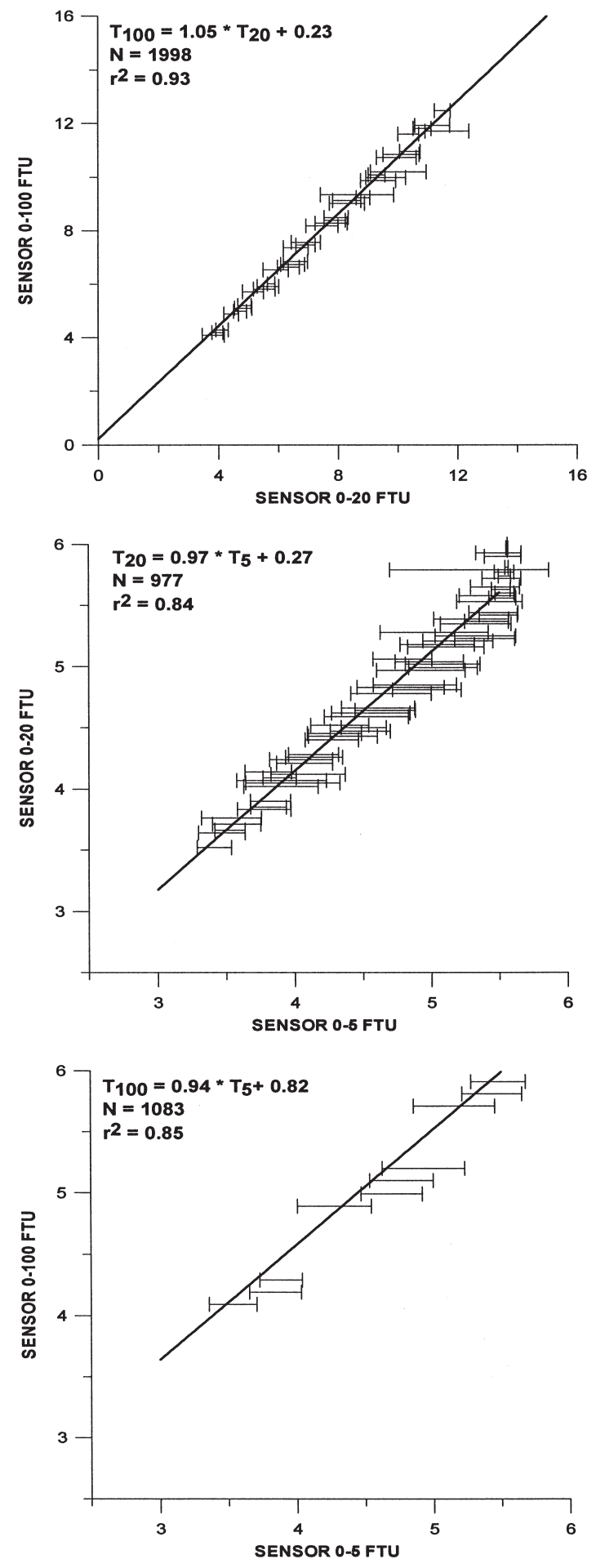

FIG. 7. - Comparison between simultaneous turbidity measurements using Aanderaa turbidimeters calibrated at different FTU ranges (segment lines indicate the sample standard deviation). The correlation coefficients between each pair of measurements are highly significant (probability $<0.1 \%$ ). The major axis linear relationship indicate that the slope and the origin are significantly different from unity and zero respectively (probability $<0.1 \%$ ) for the relations between 100 versus 20 FTU and 100 versus 5 FTU. The 20 versus 5 FTU relation displays an origin significantly different from zero (probability $<0.1 \%$ ) and the slope is not significantly different from unity. 


\section{Comparison between turbidity sensors with different calibration ranges}

An additional source of error of turbidity measurements could be the different response of each particular sensor to the water turbidity when they are set at different calibration ranges. In order to evaluate this factor, three turbidity sensors calibrated with different FTU ranges (0-5, 0-20 and 0-100) were simultaneously deployed at the same point in an estuarine, low-energy environment (the Ebro River estuary).

The major axis linear relationships between each pair of sensors are shown in Figure 7. The coefficient of determination varied between 0.84-0.85 (T100 and T20 versus T5) and 0.93 (T100 versus T20). From the regression equations, it can be observed that the sensor with the larger range always overestimated the measures from the lower range sensor. If we consider only records where turbidity values measured by the 0-5 FTU sensor were lower than 5.56 FTU, the mean turbidities for the 0-5, 0-20 and 0-100 FTU sensors are 4.53, 4.65 and 5.09 FTU, respectively. Therefore, a maximum variability of about $10 \%$ in the determination of suspended sediment concentration would result from the differences in the sensor range, probably due to the different resolution of each sensor. This means that the measured sediment fluxes will change significantly depending on the sensor range even though the calibration between the turbidity units and the SSC is accurate. Since a wide range of turbidities is measured during most field deployments, one alternative to this problem is to simultaneously use two sensors of the same type calibrated for different turbidity ranges covering the expected SSC.

\section{CONCLUDING REMARKS}

The transformation from turbidity units (BAC or FTU) to suspended sediment concentration is complex, and a general conversion relationship between the two was not found. Specific calibration curves for each instrument and for each environmental condition are required in order to obtain accurate transformations. Field calibrations are scarce and few calibrations have been done in the western Mediterranean Sea. For this reason, the review of the available (although unpublished) information obtained in successive campaigns over the last few years maybe a useful tool for the interpretation of turbidity measurements when specific calibration is unavailable. In addition they may help to design and select the most suitable turbidity ranges for future deployments in these environments.

The general calibration curves obtained from the analysed data are:

$$
\mathrm{SSC}=1.43 \alpha_{(\mathrm{p}+\mathrm{w})}-0.25\left(\mathrm{r}^{2}=0.85\right),
$$

$\mathrm{SSC}=1.74 \mathrm{FTU}-1.32\left(\mathrm{r}^{2}=0.99\right)($ for FTU $>0.2)$,

These calibrations can only be used for qualitative or semi-quantitative purposes. They represent an average approach for the environmental conditions recorded during the analysed surveys, but can significantly change under different conditions (e.g. changes in the grain size of the suspended sediment). The high correlation coefficients $\left(\mathrm{r}^{2}>0.85\right)$ in both equations suggest that the grain size of the suspended sediment did not change dramatically during the studies. Consequently, the regressions can be used for semi-quantitative purposes for suspended sediment composed of fine particles.

Lastly, the selection of the turbidity range appropriate to each condition is a relevant factor for successfully quantifying suspended sediment concentrations and fluxes. To solve this problem, we recommend the simultaneous use of two or more equivalent sensors with different calibration ranges.

\section{ACKNOWLEDGEMENTS}

Data used in this paper were collected during the projects: FANS (MAS3-CT95-0037), CONCENTRA (AMB92-0251-C02-01), FLUXALB (MAR96 -1781-CO2-01), IMPACT (CEE. REF. 95/52), METRO-MED (MAS3-CT96-0049), PNEC and CAÑONES (MAR1999-1060-C03-01).

\section{REFERENCES}

Baker, E.T. and J.W. Lavelle. - 1984. The effect of particle size on the light attenuation coefficient of natural suspensions. J. Geophys. Res., 89: 8197-8203.

Black, K.P. and M.A. Rosenberg. - 1994. Suspended sand measurements in a turbulent environment: field comparison of optical and pump sampling techniques. Coastal Engineering, 24: 137-150.

Bishop, J.K.B. - 1986. The correction of suspended particulate matter calibration of Sea Tech transmissometer data. Deep Sea Res., 33: 121-134.

Bunt, J.A.C., P. Larcombe, and C.F. Jago. - 1999. Quantifying the response of optical backscatter devices and transmissometers to 
variations in suspended particulate matter. Cont. Shelf Res., 19: 1199-1220.

Conner, C.S. and A.M. De Visser. - 1992. A laboratory investigation of particle size effects on an optical backscatterance sensor Mar. Geol., 108: 151-159.

Downing, J.P. and R.A. Beach. - 1989. Laboratory apparatus for calibrating optical suspended solids sensors. Mar. Geol.., 86 243-249.

Durrieu de Madron, X., F. Nyffeler, and C.H. Godet. - 1990 Hydrographic structure and nepheloid spatial distribution in the Gulf of Lions continental margin. Cont. Shelf Res., 10 (9-11): 915-929.

Durrieu de Madron, X., A. Calafat, J.L. Casamor, B.Charriere, P. Kerherve and P. Puig. - 1994. Preliminary report on the calibration of nephelometer measurements versus in situ measurements of suspended matter concentration. Euromarge-NW Mediterranean, Progress Report (first annual report), Vol. II

Green, M.O. and J.D. Boon. - 1993. The measurement of constituent concentrations in nonhomogeneous sediment suspensions using optical backscatter sensors. Mar. Geol., 110: 73-81.

Guillén, J., A. Palanques and P. Puig. - 1998. Field measurements of suspended sediment concentration during FANS field campaigns: a comparative analysis. Second FANS Plenary workshop meeting, Bangor, UK. 10 pp

Jerlov, H.G. - 1968. Optical oceanography, Elsevier, New York. $194 \mathrm{pp}$.

Ludwig, K.A. and D.M. Hanes. - 1990. A laboratory evaluation of optical backscatterance suspended solids sensors exposed to sand-mud mixtures. Mar. Geol., 94: 173-179.

Madsen, O.S., L.D. Wright, J.D. Boon and T.A. Chisholm. - 1993. Wind stress, bed roughness and sediment suspension on the inner shelf during an extreme storm event. Cont. Shelf Res., 13(11): 1303-1324.
Moody, J.A., B. Butman and M. Bothner. - 1987. Near-bottom suspended matter concentration on the Continental Shelf during storms: estimates based on in situ observations of light transmission and a particle size dependent transmissometer calibration. Cont. Shelf Res., 7(6): 609-628.

Puig, P. and A. Palanques. - 1998. Nepheloid structure and hydrographic control in the Barcelona continental margin, northwestern Mediterranean. Mar. Geol., 149: 39-54.

Sokal, R.R. and F.J. Rohlf. - 1981. Biometry. Second Edition. W.H. Freeman and Company, New-York: 859 pp.

Sherwood, C.R., B. Butman, D.A. Cacchione, D.E. Drake, T.F. Gross, R.W. Sternberg, P.L. Wiberg and A.J. Williams. - 1994. Sediment-transport events on the northern California continental shelf during the 1990-1991 STRESS experiment. Cont. Shelf Res., 14: 1063-1099.

Spinrad, R.W., J.R.V. Zaneveld and J.C. Kitchen. - 1983. A study of the optical characteristics of the suspended particles in the benthic nepheloid layer of the Scotian Rise. J. Geophys. Res., 88: 7641-7645.

Sutherland, T.F., P.M. Lane, C.L. Amos and J. Downing. - 2000. The calibration of optical backscatter sensors for suspended sediment of varying darkness levels. Mar. Geol., 162: 587-597.

Vangriesheim, A., J.P. Gouillou and L. Prieur. - 1992 A deep-ocean nephelometer to detect bottom and intermediate nepheloid layers. Deep-Sea Res., 39: 1403-1416.

Wiberg, P.L., D.E. Drake and D.A. Cacchione. - 1994. Sediment resuspension and bed armouring during high bottom stress events on the northern California inner continental shelf: measurements and predictions. Cont. Shelf Res., 14(10/11): 11911219.

Scient. ed.: C. Pedrós-Alió 